\title{
Production of Human Monoclonal Anti-Basement Membrane Zone (BMZ) Antibodies from a Patient with Bullous Pemphigoid (BP) by Epstein-Barr Virus Transformation
}

\author{
Analyses of the Heterogeneity of Anti-BMZ Antibodies in BP Sera Using Them
}

\author{
Toshiyuki Sugi, ${ }^{*}$ Takashi Hashimoto, ${ }^{*}$ Toshifumi Hibi, ${ }^{\ddagger}$ and Takeji Nishikawa* \\ *Department of Dermatology, Keio University School of Medicine, Tokyo 160, Japan; and ${ }^{*}$ Section of Internal Medicine, \\ Kitasato Institute Hospital, Tokyo 108, Japan
}

\begin{abstract}
We established three lymphoblastoid cell lines from a bullous pemphigoid (BP) patient's peripheral blood by means of EBV transformation, which produced human monoclonal anti-basement membrane zone (BMZ) IgG antibodies. A blocking immunofluorescence test using these MAbs, designated 5A, 5E, and $10 \mathrm{D}$, revealed that $5 \mathrm{~A}$ and $5 \mathrm{E}$ recognized the same or a closely associated epitope, but the epitope for $10 \mathrm{D}$ was completely different. 18 of $30 \mathrm{BP}$ sera blocked the reactivity of 10D MAb and 17 sera blocked 5E, while 9 sera did not block the staining of either antibody. Immunoblot analysis demonstrated that both $5 \mathrm{~A}$ and $5 \mathrm{E}$ MAbs reacted exclusively with a protein band of $\sim 230 \mathrm{kD}$ in normal human epidermal extracts. However, 10D did not show any protein band. 22 of 30 BP sera strongly reacted with the same $230-\mathrm{kD}$ protein, while none of control sera showed such reactivity.

These results clearly demonstrated the heterogeneity of anti-BMZ antibodies in terms of epitopes. These MAbs should be useful in future investigations concerning not only the immunopathology but also the biochemical and molecular analyses of the BP antigen.
\end{abstract}

\section{Introduction}

Bullous pemphigoid (BP) ${ }^{1}$ is an autoimmune skin disease characterized by tense blister formation at the dermoepidermal junction (1). The direct immunofluorescence test reveals IgG deposits along the basement membrane zone (BMZ; 2). In most cases circulating anti-BMZ antibodies are also detected by the indirect immunofluorescence (IIF) technique (3). It has recently been reported that anti-BMZ autoantibodies in the

This work was presented in part at the 50th Meeting of the Society for Investigative Dermatology, Washington, DC, 27-30 April 1988, and at the ESDR-JSID-SID Tricontinental Meeting, Washington, DC, 26-30 April 1989.

Address correspondence to Dr. T. Hashimoto, Department of Dermatology, Keio University School of Medicine, 35 Shinano-machi, Shinjuku-ku, Tokyo 160, Japan.

Received for publication 12 January 1989 and in revised form 31 May 1989.

1. Abbreviations used in this paper: BMZ, basement membrane zone; BP, bullous pemphigoid; IIF, indirect immunofluorescence; TBS, Tris (hydroxymethyl) aminomethane hydrochloride-buffered saline.

J. Clin. Invest.

(c) The American Society for Clinical Investigation, Inc. $0021-9738 / 89 / 10 / 1050 / 06 \$ 2.00$

Volume 84, October 1989, 1050-1055 sera from BP patients play important roles in its pathogenesis (4-8). Furthermore, some investigators have suggested the heterogeneity of the antibodies (9-15), while others have implied that BP antibody recognizes a single unique antigen (16-21).

Recently, production of human MAbs using EBV transformation (22-27) or hybridoma techniques (28-32) has made a marked advance, and it has contributed to the progress in various fields of research, although this approach has not been applied to autoimmune blistering diseases such as BP and pemphigus. In this study we have tried to elaborate human monoclonal anti-BMZ antibodies by EBV transformation and to examine the heterogeneity of the anti-BMZ antibodies in BP sera.

\section{Methods}

Patients and sera. Peripheral blood lymphocytes were obtained from a 72-yr-old male BP patient having anti-BMZ antibodies in the sera at a titer of 320. Sera for blocking immunofluorescence and Western blot experiments were obtained from 30 confirmed BP patients possessing circulating antibodies at titers of $40-2,560$ by IIF test.

$I I F$. IIF was performed according to the previously established method $(2,3)$ using normal human skin section as a substrate. All of FITC-conjugated anti-human IgG ( $\gamma$-chains), IgM ( $\mu$-chains), $\operatorname{IgA}(\alpha$ chains), and $\operatorname{IgE}$ ( $\epsilon$-chains) rabbit antisera were purchased from DAKO, Copenhagen, Denmark, and used at a dilution of 1:10-1:20.

Lymphocyte preparation. $20 \mathrm{ml}$ of heparinized peripheral blood was obtained by venipuncture. Mononuclear cells were isolated by centrifugation on Lymphoprep (Nycomed AS, Oslo, Norway). Cells were washed three times with PBS and rosetted with neuraminidasetreated sheep erythrocytes. The rosetted cells were removed by centrifugation on Lymphoprep. The B lymphocyte-enriched fraction was washed three times with PBS and used for the following experiments.

$E B V$ transformation. EBV was obtained from the culture supernatant of the B95-8 marmoset cell line. $2 \times 10^{5} / \mathrm{ml}$ B95-8 cells were cultured in $5 \% \mathrm{CO}_{2}$ humidified incubator at $37^{\circ} \mathrm{C}$ with RPMI 1640 (Gibco Laboratories, Grand Island, NY) supplemented with 10\% FCS and penicillin/streptomycin (Gibco Laboratories) for $8 \mathrm{~d}$ without medium change (33). The supernatant containing EBV was harvested, filtered through a $0.45-\mu \mathrm{m}$ filter (Millipore Japan, Yamagata, Japan), and stored at $-70^{\circ} \mathrm{C}$. Peripheral blood lymphocytes prepared as previously mentioned were incubated with $1 \mathrm{ml}$ of supernatant containing $\mathrm{EBV}$ for $2 \mathrm{~h}$ at $37^{\circ} \mathrm{C}$ with occasional swirling. After incubation the cells were washed three times with PBS, resuspended in $20 \mathrm{ml}$ RPMI 1640 with $20 \%$ FCS and penicillin/streptomycin, and $0.2 \mathrm{ml}$ of suspended medium was seeded in each well of a 96-well culture plate (Falcon Plastics, Cockeysville, MD). The plate was placed in a $5 \% \mathrm{CO}_{2}$ humidified atmosphere, and half of the medium was changed every fourth day until colonies grew enough for screening assay.

Screening assay. Supernatants from wells with colony formation were screened for anti-BMZ antibodies by IIF, using FITC-conjugated anti-human IgG antiserum as a second antibody. 
Cloning. The transformants producing anti-BMZ antibodies were cloned in 96-well plates by a limiting dilution method on feeder layers of cord blood lymphocytes that had been previously treated with 20 $\mu \mathrm{g} / \mathrm{ml}$ mitomycin C (Kyowa Hakko, Tokyo, Japan) for $30 \mathrm{~min}$. Supernatants from wells with growing colonies were again tested by IIF for the presence of anti-BMZ antibodies.

Study for IgG subclasses. IgG subclasses of the antibodies were determined by IIF using anti-human IgG subclass mouse MAbs as previously described (34).

Biotinylation of the antibodies. Cloned lymphoblastoid cell lines were cultured with serum-free medium, S-clone SF-B (Sankou Junyaku, Tokyo, Japan). IgG was prepared from the supernatant by salt precipitation with $50 \%$ saturated ammonium sulphate. Biotinylation of IgG was performed according to the previously reported method (35).

Blocking immunofluorescence experiments. To characterize the epitopes recognized by the human MAbs, a blocking immunofluorescence test was performed according to the previously described method with minor modifications $(11,36)$. Normal human skin sections were pretreated with IgG solution purified from culture supernatant containing anti-BMZ MAbs or with the diluted sera from BP patients or normal controls for $30 \mathrm{~min}$ at $37^{\circ} \mathrm{C}$, and subsequently incubated with diluted biotin-conjugated human MAbs for $30 \mathrm{~min}$ at $37^{\circ} \mathrm{C}$, followed by incubation with $1: 1,000$ diluted FITC-conjugated egg white avidin (Tago Inc., Burlingame, CA) for $30 \mathrm{~min}$ at room temperature. Between each treatment the sections were rinsed for 15 min with three changes of cooled PBS. The preparations were observed by epifluorescence microscope (BH2-RFL; Olympus, Tokyo, Japan).

Immunoblot analysis. Immunoblotting was performed mainly according to the method described by Labib et al. (15). Adult foreskin was obtained at circumcision surgery. Skin pieces prepared by forceps and scissors were incubated in PBS containing 2 mM EDTA (Nakarai Tesque, Kyoto, Japan) and $2 \mathrm{mM}$ PMSF (Sigma Chemical Co., St. Louis, $\mathrm{MO}$ ) for $2 \mathrm{~d}$ at $4^{\circ} \mathrm{C}$, and epidermis was peeled off by forceps as previously reported (37). This epidermis preparation was confirmed to retain BP antigen by IIF. The pieces of epidermis were collected and homogenized by glass homogenizer in an ice-water bath with $1 \%$ SDS, $0.01 \mathrm{M}$ Tris (hydroxymethyl) aminomethane hydrochloride buffer (Nakarai Tesque) supplemented with 2 mM EDTA, 2 mM PMSF, 5 $\mathrm{mg} /$ liter each of four proteinase inhibitors (leupeptin, antipain, chymostatin, and pepstatin A; Sigma Chemical Co.), and 5\% $\beta$-mercaptoethanol (Kanto Chemical Co., Tokyo, Japan), pH 6.8. The homoge- nized sample was boiled for 5 min and centrifuged. Supernatant was harvested and stored at $-70^{\circ} \mathrm{C}$ as aliquots. SDS-PAGE was performed by Laemmli's method (38) using $6 \%$ separating gel. Separated proteins were electrophoretically transferred to a nitrocellulose sheet (Schleicher and Schuell, Dassel, FRG; 39). For immunostaining, strips of blotted sheet were first blocked by 3\% skimmed milk (Morinaga, Tokyo, Japan) in Tris (hydroxymethyl) aminomethane hydrochloride buffered saline (TBS) for $2 \mathrm{~h}$ at room temperature. Blocked strips were treated with MAbs or sera from BP patients or normal individuals diluted with $3 \%$ skimmed milk overnight at $4^{\circ} \mathrm{C}$. Subsequently the strips were reacted with peroxidase-conjugated anti-human IgG $(\gamma-$ chains) rabbit antiserum (DAKO) diluted at $1: 100$ with $3 \%$ skimmed milk in TBS for $2 \mathrm{~h}$. Between each treatment the strips were washed for 15 min with three changes of TBS containing $0.5 \%$ Tween 20 (Sigma Chemical Co.). Finally, color was developed by 4-chloro-1-naphthol (Bio-Rad Laboratories, Richmond, CA) in the presence of hydrogen peroxide.

Protein measurement and IgG purification from BP sera. Total protein was determined by the method of Lowry et al. (40) using BSA as a standard. IgG fractions were isolated from several BP sera by salt precipitation with $50 \%$ saturated ammonium sulphate, followed by protein A-Sepharose CL-4B (Pharmacia AB, Uppsala, Sweden) affinity chromatography (41). The eluate was dialyzed against PBS containing $0.1 \% \mathrm{NaN}_{3}$ and concentrated on a concentrator (Centriprep 10; Amicon Corp., Danvers, MA).

\section{Results}

Establishment of lymphoblastoid cell lines. B lymphocytes infected with EBV were cultured for 3 wk in a 96-well plate. Most wells showed colony formation. Screening test demonstrated that six wells were positive for anti-BMZ antibodies. Three were not stable and the production of antibody decreased rapidly. The remaining three wells (designated 5A, 5E, and 10D) were cloned by the limiting dilution method. Each clone was again confirmed by IIF to produce anti-BMZ IgG antibody (Fig. 1), but no IgM, IgA, or IgE antibodies were found. All wells with colony formation showed the presence of anti-BMZ antibodies, which suggested that monoclonality of the antibodies had been almost achieved in the initial cultures.

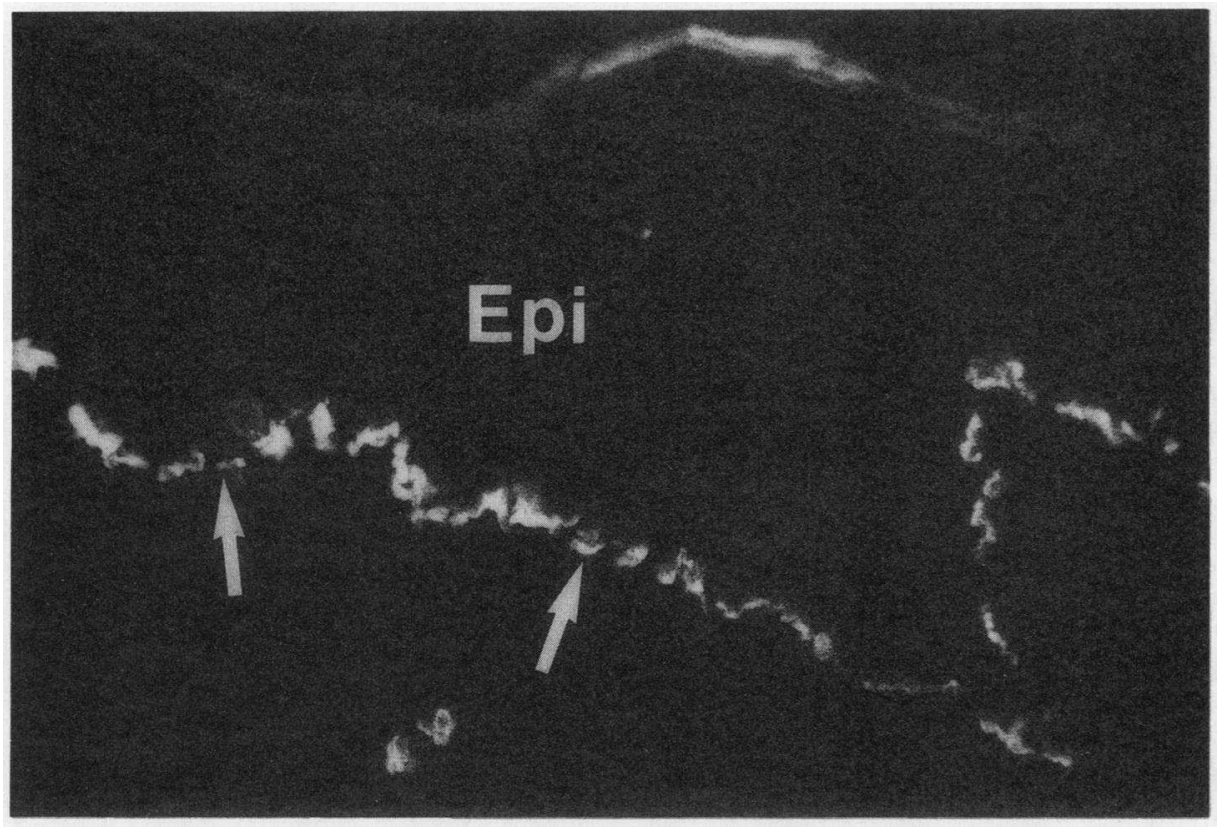

Figure 1. IIF staining by 10D human monoclonal anti-BMZ antibody using EDTA separated human epidermis as a substrate. Positive reaction is seen discontinuously along the BMZ of epidermis $(\times 200)$. Arrows, BMZ; Epi, epidermis. 
These cell lines continued to produce antibodies for more than 6 mo until cells were frozen to be stored. The IgG subclass was analyzed for three clones and for the serum from the donor BP patient. All three human MAbs were IgG2, while the serum of the donor contained IgG1, IgG2, and IgG4, but not IgG3, autoantibodies.

IgG isolation from the supernatant of lymphoblastoid cell cultures and biotinylation. Total protein concentration and the terminal dilution point for IIF were determined for each of the IgG fractions prepared from the culture supernatant of lymphoblastoid cells and the biotin conjugate. Total protein concentrations in undiluted solutions and the terminal dilution points, respectively, were as follows: $6 \mathrm{mg} / \mathrm{ml}$ and 1:640 for $5 \mathrm{~A}$ IgG; $12 \mathrm{mg} / \mathrm{ml}$ and $1: 2,560$ for $5 \mathrm{E} \mathrm{IgG;} 1.2 \mathrm{mg} / \mathrm{ml}$ and $1: 160$ for $10 \mathrm{D} \mathrm{IgG;} 6 \mathrm{mg} / \mathrm{ml}$ and $1: 160$ for biotinylated $5 \mathrm{~A} ; 10$ $\mathrm{mg} / \mathrm{ml}$ and $1: 640$ for biotinylated $5 \mathrm{E}$; and $1.5 \mathrm{mg} / \mathrm{ml}$ and $1: 40$ for biotinylated 10D. To correspond to the titers of BP sera and make a comparison easier, dilution instead of protein concentration was used for these solutions in the following experiments.

Blocking immunofluorescence experiments. For this test, biotin-conjugated monoclonal anti-BMZ antibodies were used at dilutions that were four times as high as the terminal dilution point of each conjugate (i.e., 1:40 for $5 \mathrm{~A}, 1: 160$ for $5 \mathrm{E}$, and 1:10 for 10D). The sera diluted in this way will be stated as fourfold concentrated sera hereafter. In all experiments both blocking test and serum titration by IIF were performed simultaneously. Serum dilutions tested for blocking effect and titration were $1: 2.5-1: 640$ and $1: 10-1: 2,560$, respectively. When 16-fold concentrated sera or MAbs were able to block the reactivities of biotinylated antibodies, the blocking capability of these sera or MAbs was arbitrarily designated as positive.

To determine the identity among the three MAbs, the blocking effect of each purified MAb on individual conjugate was first examined. BMZ staining of all biotinylated MAbs was blocked by pretreatment of the purified IgG of each corresponding MAb. Reactivity of biotinylated 5A was blocked by $5 \mathrm{E}$ but not $10 \mathrm{D}$. Reaction of conjugated $5 \mathrm{E}$ was blocked by $5 \mathrm{~A}$ but not 10D. Further, reaction of 10D was not blocked by $5 \mathrm{~A}$ or $5 \mathrm{E}$. Fourfold-concentrated $5 \mathrm{~A}$ and $5 \mathrm{E}$ IgGs still showed blocking effects on biotinylated $5 \mathrm{~A}$ and $5 \mathrm{E}$. On the contrary, even 64 -fold concentrated $10 \mathrm{D} \mathrm{IgG}$ did not block the reactivities of $5 \mathrm{~A}$ or $5 \mathrm{E}$.

Since $5 \mathrm{~A}$ and $5 \mathrm{E}$ were found to react with the same or a closely associated epitope, only $5 \mathrm{E}$ and $10 \mathrm{D}$ conjugates were used for further studies on blocking effect of BP sera. Results of the blocking effect of BP sera are summarized in Table I. The reactivity of biotinylated $5 \mathrm{E}$ was blocked by 17 of the 30 BP sera tested. BMZ staining of 10D was blocked by $18 \mathrm{BP}$ sera. Reactivities of both $5 \mathrm{E}$ and 10D MAbs were blocked by sera from 14 BP patients, including the donor BP patient. Three sera showed a blocking effect on $5 \mathrm{E}$ reactivity but not on 10D, while four sera blocked only 10D. Nine BP sera did not block either 5E or 10D. Absence of the blocking effect on these sera was obvious even at 64 - to 256 -fold concentrations. None of the 18 normal sera showed this blocking effect.

Immunoblot analysis (Fig. 2) and its relation to blocking immunofluorescence. By immunoblotting, 5E MAb showed reactivity with a single protein band of an apparent molecular mass of $230 \mathrm{kD}$. $5 \mathrm{~A}$ also stained the same band exclusively. However, 10D did not demonstrate any protein band even when nondiluted IgG sample was used. $30 \mathrm{BP}$ sera were also
Table I. Results of Blocking Immunofluorescence and Immunoblot Labeling of $30 \mathrm{BP}$ Sera

\begin{tabular}{lccccc}
\hline & \multicolumn{4}{c}{ Blocking effect on (5E, 10D) } & \\
\cline { 2 - 5 } $\begin{array}{l}\text { Immunoblot labeling of } \\
(230 \mathrm{kD}, 170 \mathrm{kD})\end{array}$ & $(+,+)^{*}$ & $(+,-)$ & $(-,+)$ & $(-,-)$ & $\begin{array}{r}\text { Total No. } \\
\text { of the sera }\end{array}$ \\
\hline$(+,+)^{\ddagger}$ & 5 & 2 & 1 & 2 & $10 / 30$ \\
$(+,-)$ & 7 & 0 & 2 & 3 & $12 / 30$ \\
$(-,+)$ & 0 & 0 & 0 & 2 & $2 / 30$ \\
$(-,-)$ & 2 & 1 & 1 & 2 & $6 / 30$ \\
$\begin{array}{l}\text { Total No. of the } \\
\text { sera }\end{array}$ & $14 / 30$ & $3 / 30$ & $4 / 30$ & $9 / 30$ & \\
\hline
\end{tabular}

This table shows the combined data of the results of blocking immunofluorescence and immunoblot analysis of $30 \mathrm{BP}$ sera. The bottom line indicates the total No. for the blocking experiments, and the right column indicates the total No. for immunoblot analyses.

* The reactivities of both $5 \mathrm{E}$ and $10 \mathrm{D}$ were blocked by the 16 -fold concentrated BP sera.

${ }^{\ddagger}$ Both the 230 - and $170-k D$ bands were stained by the 1:40 diluted BP sera.

examined by immunoblotting as shown in Table I. 22 sera reacted strongly with the same $230-\mathrm{kD}$ protein band. In addition, 12 sera specifically stained a protein band of $\sim 170 \mathrm{kD}$. 10 sera yielded both 230 - and $170-\mathrm{kD}$ bands, 12 sera showed only a $230-\mathrm{kD}$ band and 2 sera showed only a $170-\mathrm{kD}$ band. Six BP sera did not react with either protein band. None of 18 normal sera showed reactivity with either band. No specific correlation between the results of blocking immunofluorescence and immunoblotting was observed in this table.

Because $5 \mathrm{E}$ MAb reacted with the $230-\mathrm{kD}$ protein, we studied the relationship between the blocking effect on $5 \mathrm{E}$ reactivity and the staining of the $230-\mathrm{kD}$ band on immunoblotting of individual BP serum (Table II). 14 of 30 BP sera showed both the blocking effect on $5 \mathrm{E}$ and staining of the $230-\mathrm{kD}$ band. Three sera showed a clear blocking effect on $5 \mathrm{E}$, although they did not stain the $230-\mathrm{kD}$ band on immunoblotting. Furthermore, eight sera that stained the $230-\mathrm{kD}$ band did not block $5 \mathrm{E}$ reactivity. Five sera did not show either the blocking effect or staining.

\section{Discussion}

We established three individual lymphoblastoid cell lines that continued to produce human monoclonal anti-BMZ IgG antibodies for more than 6 mo. That all cloned wells with colony formation contained anti-BMZ antibodies in the supernatant safely confirmed the monoclonality of these antibodies. This was further substantiated by the fact that immunoblot analysis showed a single positive band reacted with $5 \mathrm{~A}$ and $5 \mathrm{E}$ antibodies. The IgG subclass study revealed that all of our antibodies were of the IgG2 subclass. It remains unknown why only IgG2-producing B cells were preferentially transformed, despite the fact that the patient's serum contained IgG1, IgG2, and IgG4 anti-BMZ antibodies.

There are many previous reports about the establishment of lymphoblastoid cell lines by EBV transformation, which produced a variety of human monoclonal autoantibodies (22-27). Most of them belonged to the IgM subtype. However, 


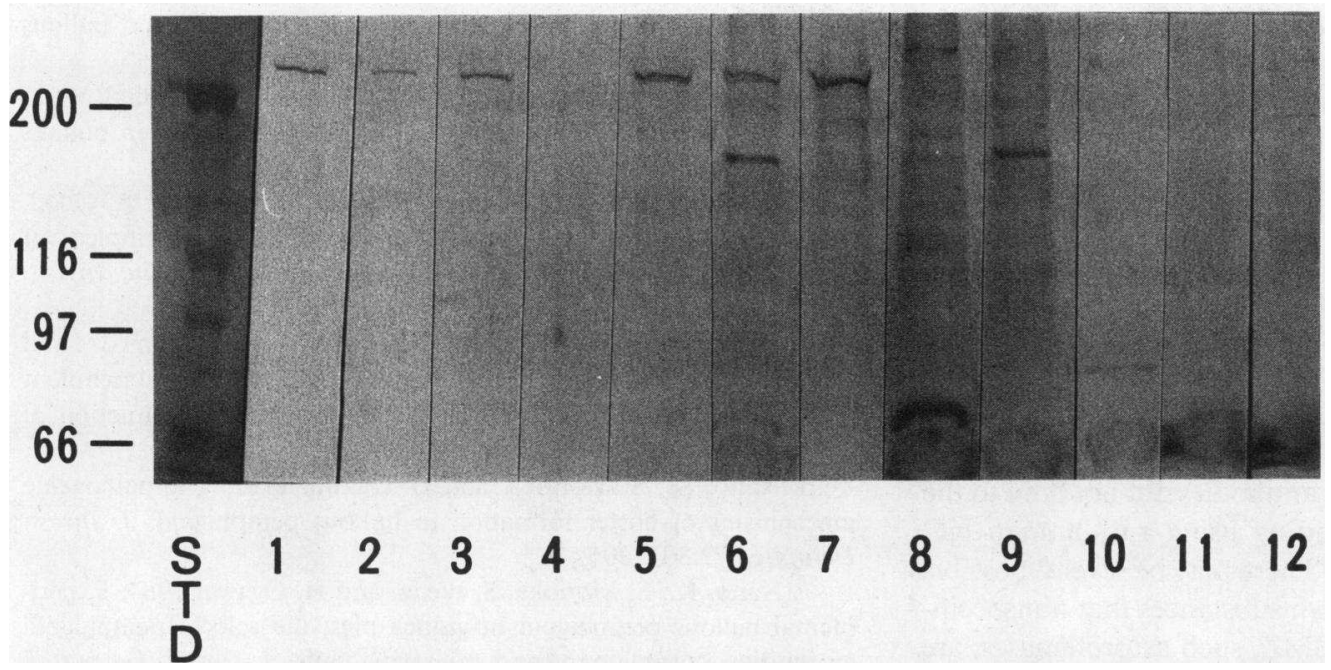

Figure 2. Immunoblot analysis. BP antigen extracted from normal human epidermis was electrophoresed and stained with human MAbs or 1:40 diluted sera from BP patients or normal controls. SE antibody reacted with a single protein band of $\sim 230 \mathrm{~mol}$ wt at dilutions of 1:160 and 1:640 (lanes 1 and 2 , respectively). $5 \mathrm{~A}$ showed the same band at 1:40 dilution (lane 3). 10D did not show any reactivity at $1: 10$ dilution (lane 4). In five representative BP sera two showed a single band of 230 kD (lanes 5 and 7), one serum showed both 230- and 170-kD bands (lane 6) (this was the serum from the donor BP patient for the lymphoblastoid cell lines), one serum showed only the 170-kD band (lane 9), and one serum showed neither band (lane 8 ). Normal sera did not react with either band (lanes 10-12). Left lane (STD) showed molecular weight standards, the apparent molecular weights of which are indicated in the left margin $\left(\times 10^{3}\right)$.

we have found no previous reports on human monoclonal IgG antibodies against epidermal components such as anti-BMZ antibodies in BP or anti-intercellular antibodies in pemphigus. Very recently, Rico and Hall (42) have reported the production of human monoclonal anti-BMZ antibodies that belonged to the IgM subtype. Since IgG anti-BMZ antibodies are predominant and IgM antibodies are rarely found by IIF in sera of BP patients, IgG antibodies are considered to be more relevant to pathogenesis in BP. Therefore, our human monoclonal anti-BMZ antibodies should be useful in many ways to study the role of autoantibodies in the pathogenesis in BP.

In this study we performed two sets of experiments using our MAbs: blocking immunofluorescence and immunoblotting. Using blocking immunofluorescence we demonstrated that $5 \mathrm{~A}$ and $5 \mathrm{E}$ MAbs reacted with the same or a closely associated epitope of the antigen, but the epitope for 10D was completely different. Furthermore, $5 \mathrm{E}$ reactivity was blocked by 17 of the $30 \mathrm{BP}$ sera tested, and 10D was blocked by $18 \mathrm{BP}$ sera, while neither reactivity was blocked by $9 \mathrm{BP}$ sera. Al-

Table II. The Relationship between the Blocking Effect on $5 E$ $M A b$ Reactivity and the Presence of the 230-kD Protein Band on Immunoblotting in 30 BP Sera

\begin{tabular}{ccc}
\hline $\begin{array}{c}\text { Blocking effect } \\
\text { on 5E }\end{array}$ & $\begin{array}{c}\text { Presence of the } \\
\text { 230-kD band }\end{array}$ & $\begin{array}{c}\text { No. of } \\
\text { BP sera }\end{array}$ \\
\hline$(+)^{*}$ & $(+)^{\S}$ & $14 / 30$ \\
$(+)$ & $(-)^{\prime \prime}$ & $3 / 30$ \\
$(-)^{\ddagger}$ & $(+)$ & $8 / 30$ \\
$(-)$ & $(-)$ & $5 / 30$ \\
\hline
\end{tabular}

\footnotetext{
* The reactivity of $5 \mathrm{E}$ was blocked by the 16 -fold concentrated $\mathrm{BP}$ sera, or ${ }^{\ddagger}$ it was not blocked by the BP sera on blocking immunofluorescence test.

${ }^{\S}$ The $230-\mathrm{kD}$ band was stained by the $1: 40$ diluted BP sera, or "it was not stained by the BP sera on immunoblot analysis.
}

though 14 sera blocked both 5E and 10D, 7 sera blocked either $5 \mathrm{E}$ or 10D. These results indicate that there should be more than three different epitopes with which antibodies in BP sera react. Further, both $5 \mathrm{E}$ and $10 \mathrm{D}$ antibodies are considered to be frequent in the sera from many BP patients.

Recently a series of studies by Stanley and others have suggested that BP sera specifically recognized a unique protein with a molecular mass of $220-240 \mathrm{kD}$ by means of immunoprecipitation $(16-21)$ and immunoblot $(17,19)$ techniques. Labib et al. (15) also found the similar $240-\mathrm{kD}$ protein band, but in addition they found another specific antigenic protein of $180 \mathrm{kD}$ using immunoblotting.

Using the same procedure of immunoblotting as Labib et al. (15), we demonstrated that 5A and 5E MAbs reacted exclusively with a $\sim 230-\mathrm{kD}$ protein from human epidermal extracts. However, 10D antibodies did not show any band on immunoblot analysis. This result further confirmed the different nature of $10 \mathrm{D}$ antibodies from those of $5 \mathrm{~A}$ and $5 \mathrm{E}$. Furthermore, we observed that 22 of 30 BP sera reacted with the identical $230-\mathrm{kD}$ protein. In addition, we detected the reactivity to $170 \mathrm{kD}$ in $12 \mathrm{BP}$ sera, while none of 18 normal sera showed either band. Our results appeared to confirm the result reported by Labib et al. (15). However, as Stanley et al. $(17,19)$ used different immunoblot techniques from Labib's and ours, we are unable to completely exclude the possibility that the $170-\mathrm{kD}$ band was merely a nonspecific reaction. The fact that 10D antibody failed to yield any stained band on immunoblotting may indicate the presence of additional BP antigen different from that identified as the $230-\mathrm{kD}$ band by $5 \mathrm{~A}$ and $5 \mathrm{E}$. However, it is also possible that $10 \mathrm{D}$ antibody reacts with a different epitope of the same $230-\mathrm{kD}$ protein and this epitope may be destroyed or masked during the procedure of immunoblotting.

The accuracy of the blocking immunofluorescence test used in this study is supported by three observations: $(a)$ the reactivity of each biotinylated antibody was blocked by the corresponding IgG fraction; $(b)$ the reactivities of $5 \mathrm{~A}$ and $5 \mathrm{E}$ MAbs were blocked by each other; and (c) the majority of BP sera were able to block the reactivity of all MAbs, in contrast to 
the absence of such an effect with any of the normal sera. These results suggested that the blocking effect was due to the presence of IgG reacting with the same epitope. Nevertheless, several discrepancies existed between the results of blocking immunofluorescence and Western blot experiments for $5 \mathrm{E}$ MAb. Although 14 of $30 \mathrm{BP}$ sera showed both blocking effect and reactivity with the $230-\mathrm{kD}$ protein, and $5 \mathrm{BP}$ sera did not show either, $8 \mathrm{BP}$ sera that recognized the $230-\mathrm{kD}$ protein on immunoblotting did not block $5 \mathrm{E}$ antibody. This may be because these sera contained antibodies reacting with epitope(s) of the $230-\mathrm{kD}$ protein different from that recognized by $5 \mathrm{E}$ antibody. Another discrepancy was that three sera that were able to block the reactivity of $5 \mathrm{E}$ antibodies did not bind to the 230-kD antigen on immunoblotting using anti-human IgG antiserum as a second antibody. There may be several possible explanations for this: $(a)$ unknown substances that nonspecifically destroy antigenic sites in $\mathrm{BMZ}$, such as proteinases, are present in some of BP sera but not in normal sera; $(b)$ these sera possess Ig other than IgG reacting with the same epitope for 5E antibody; and $(c)$ these sera bind to an epitope on the $230-\mathrm{kD}$ molecule near enough to the $5 \mathrm{E}$ epitope to block the latter by steric hindrance, but the former is destroyed by denaturation for immunoblotting, whereas the $5 \mathrm{E}$ epitope is not. To solve this issue, immunoblotting was performed using peroxidase-conjugated anti-human IgM, IgA, and IgE antisera as second antibodies. This study revealed that three sera possessed both IgM and IgE types of Ig, which clearly reacted with the $230-\mathrm{kD}$ protein (data not shown). Furthermore, IgG fractions purified from these sera by protein A chromatography did not show blocking effects on $5 \mathrm{E}$ reactivity by blocking immunofluorescence. These results suggested that the blocking effect on $5 \mathrm{E}$ reactivity of these sera might be due to the presence of IgM and/or IgE antibodies reacting with the same epitope of the $5 \mathrm{E}$ antibody.

For several years there have been many arguments about the heterogeneity of anti-BMZ antibodies in BP sera (9-20). The results in the present study clearly demonstrate the diversity of epitopes that bind to anti-BMZ antibodies. However, as we have not found any molecules on immunoblotting other than $230 \mathrm{kD}$ using our MAbs, the problem of the molecular heterogeneity of BP antigen must be solved by further investigation.

The human monoclonal anti-BMZ antibodies we established should be extremely valuable for various fields of investigation, such as immunopathology, cellular immunology, biochemistry, and molecular biology, and should be used to reveal the mechanisms of blister formation in BP. Further investigations using these MAbs are in progress in our laboratory.

\section{Acknowledgments}

We thank Dr. K. Konishi for preparation of the manuscript and Mrs. S. Hashimoto for typing the manuscript.

This work was supported by Grant-in-aid for Scientific Research from the Ministry of Education, Science and Culture of Japan (62770753), and by a grant from the Ministry of Welfare and Health of Japan.

\section{References}

1. Lever, W. F. 1953. Pemphigus. Medicine (Baltimore). 32:1-123.

2. Jordon, R. E., R. Minn, C. T. Triftshauser, and A. L. Schroeter.
1971. Direct immunofluorescent studies of pemphigus and bullous pemphigoid. Arch. Dermatol. 103:486-491.

3. Jordon, R. E., E. H. Beutner, E. Witebsky, G. Blumental, W. L. Hale, and W. F. Lever. 1967. Basement zone antibodies in bullous pemphigoid. JAMA (J. Am. Med. Assoc.). 200:91-96.

4. Jordon, R. E., N. K. Day, W. M. Sams, Jr., and R. A. Good. 1973. The complement system in bullous pemphigoid. I. Complement and component levels in sera and blister fluids. J. Clin. Invest. 52:1207-1214.

5. Gammon, W. R., D. M. Lewis, J. R. Carls, W. M. Sams, Jr., and C. E. Wheeler, Jr. 1980. Pemphigoid antibody-mediated attachment of peripheral blood leukocytes at the dermo-epidermal junction of human skin. J. Invest. Dermatol. 75:334-339.

6. Naito, K., S. Morioka, and H. Ogawa. 1982. The pathogenic mechanisms of blister formation in bullous pemphigoid. $J$. Invest. Dermatol. 79:303-306.

7. Naito, K., S. Morioka, S. Ikeda, and H. Ogawa. 1984. Experimental bullous pemphigoid in guinea pigs: the role of pemphigoid antibodies, complement and migrating cells. J. Invest. Dermatol. 82:227-230.

8. Haustein, U.-F. 1989. The role of bullous pemphigoid antibodies in dermal-epidermal separation. J. Invest. Dermatol. 92:133.

9. Diaz, L. A., N. J. Calvanico, T. B. Tomasi, and R. E. Jordon. 1977. Bullous pemphigoid antigen: isolation from normal human skin. J. Immunol. 118:455-460.

10. Diaz, L. A., H. Patel, and N. J. Calvanico. 1979. Bullous pemphigoid antigen. II. Isolation from the urine of a patient. J. Immunol. 122:605-608.

11. Nishikawa, T., S. Kurihara, T. Harada, and H. Hatano. 1980. Binding of bullous pemphigoid antibodies to basal cells. J. Invest. Dermatol. 74:389-391.

12. Zhu, X. J., and J. C. Bystryn. 1983. Heterogeneity of pemphigoid antigens. J. Invest. Dermatol. 80:16-20.

13. Yamasaki, Y., and T. Nishikawa. 1983. Ultrastructural localization of in vitro binding sites of circulating anti-basement membrane zone antibodies in bullous pemphigoid. Acta Dermato-venereol. 63:501-506.

14. Muramatsu, T., T. Shirai, T. Iida, Y. Yamashina, and K. Sakamoto. 1988. Antigen specificities of antibasement membrane zone antibodies: immunofluorescence and Western immunoblotting studies. Arch. Dermatol. Res. 280:411-415.

15. Labib, R. S., G. J. Anhalt, H. P. Patel, D. F. Mutasim, and L. A. Diaz. 1986. Molecular heterogeneity of the bullous pemphigoid antigens as detected by immunoblotting. J. Immunol. 136:1231-1235.

16. Stanley, J. R., P. Hawley-Nelson, S. H. Yuspa, E. M. Shevach, and S. I. Katz. 1981. Characterization of bullous pemphigoid antigen: a unique basement membrane protein of stratified squamous epithelia. Cell. 24:897-903.

17. Stanley, J. R., D. T. Woodley, and S. I. Katz. 1984. Identification and partial characterization of pemphigoid antigen extracted from normal human skin. J. Invest. Dermatol. 82:108-111.

18. Thivolet, C. H., H. H. Hintner, and J. R. Stanley. 1984. The effect of retinoic acid on the expression of pemphigus and pemphigoid antigens in cultured human keratinocytes. J. Invest. Dermatol. 82:329-334.

19. Stanley, J. R. 1985. A specific antigen-antibody interaction triggers the cellular pathophysiology of bullous pemphigoid. $B r . J$. Dermatol. 113:67-73.

20. Mueller, S., V. Klaus-Kovtum, and J. R. Stanley. 1989. A 230-kD basic protein is the major bullous pemphigoid antigen. $J$. Invest. Dermatol. 92:33-38.

21. Okada, N., Y. Kitano, S. Miyagawa, K. Sakamoto, and M. L. Steinberg. 1986. Expression of pemphigoid antigen by SV-40 transformed human keratinocytes. J. Invest. Dermatol. 86:399-401.

22. Steinitz, M., G. Klein, S. Koskimies, and O. Makel. 1977. EB virus-induced B lymphocyte cell lines producing specific antibody. Nature (Lond.). 269:420-422.

23. Steinitz, M., G. Izak, S. Cohen, M. Ehrenfeld, and I. Flechner. 
1980. Continuous production of monoclonal rheumatoid factor by EBV-transformed lymphocytes. Nature (Lond.). 287:443-445.

24. Irie, R. F., L. L. Sze, and R. E. Saxton. 1982. Human antibody to OFA-I, a tumor antigen, produced in vitro by Epstein-Barr virustransformed human B-lymphoid cell lines. Proc. Natl. Acad. Sci. USA. 79:5666-5670.

25. Watson, D. B., G. F. Burns, and I. R. Mackay. 1983. In vitro growth of B lymphocytes infiltrating human melanoma tissue by transformation with EBV: evidence for secretion of anti-melanoma antibodies by some transformed cells. J. Immunol. 130:2442-2447.

26. Garzelli, C., F. E. Taub, M. C. Jenkins, D. W. Drell, F. Ginsberg-Fellner, and A. L. Notkins. 1986. Human monoclonal autoantibodies that react with both pancreatic islets and thyroid. J. Clin. Invest. 77:1627-1631

27. Hibi, T., M. A. Chan, D. Petsche, and H.-M. Dosch. 1986. Phenotype, frequency and EBV responsiveness of human marrow B and pre-B cells. J. Immunol. 136:3211-3217.

28. Olsson, L., and H. S. Kaplan. 1980. Human-human hybridomas producing monoclonal antibodies of defined antigenic specificity. Proc. Natl. Acad. Sci. USA. 77:5429-5431.

29. Edwards, P. A. W., C. M. Smith, A. M. Neville, and M. J. O'Hare. 1982. A human-human hybridoma system based on a fastgrowing mutant of the ARH-77 plasma cell leukemia-derived line. Eur. J. Immunol. 12:641-648.

30. Cote, R. J., D. M. Morrissey, A. N. Houghton, E. J. Beattie, Jr., H. F. Oettgen, and L. J. Old. 1983. Generation of human monoclonal antibodies reactive with cellular antigens. Proc. Natl. Acad. Sci. USA. 80:2026-2030.

31. Croce, C. M., A. Linnenbach, W. Hall, Z. Steplewski, and H. Koprowski. 1980. Production of human hybridomas secreting antibodies to measles virus. Nature (Lond.). 288:488-489.

32. Nowinski, R., C. Berglund, J. Lane, M. Lastrom, I. Bernstein, W. Young, S. Hakomori, L. Hill, and M. Cooney. 1980. Human monoclonal antibody against Forssman antigen. Science (Wash. DC). 210:537-539.
33. Ichimori, Y., K. Harada, S. Hitotsumachi, and K. Tsukamoto. 1987. Establishment of hybridoma secreting human monoclonal antibody against hepatitis B virus surface antigen. Biochem. Biophys. Res. Commun. 142:805-812.

34. Yamada, H., T. Hashimoto, and T. Nishikawa. 1989. IgG subclasses of intercellular and basement membrane zone antibodies: the relationship to the capability of complement fixation. J. Invest. Dermatol. 92:585-587.

35. Heggeness, M. H., and J. F. Ash. 1977. Use of the avidin-biotin complex for the localization of actin and myosin with fluorescent microscopy. J. Cell Biol. 73:783-788.

36. Wood, W. G., and R. E. Beutner. 1977. Blocking immunofluorescence studies on the specificity of pemphigus autoantibodies. Clin. Immunol. Immunopathol. 7:168-175.

37. Scaletta, L. J., J. C. Occhino, D. K. MacCallun, and J. H. Lillie. 1978. Isolation and immunologic identification of basement membrane zone antigens from human skin. Lab. Invest. 39:1-9.

38. Laemmli, U. K. 1970. Cleavage of structural proteins during the assembly of the head of bacteriophage T4. Nature (Lond.). 227:680-685.

39. Towbin, H., T. Staehelin, and J. Gordon. 1979. Electrophoretic transfer of proteins from polyacrylamide gels to nitrocellulose sheets: procedure and some applications. Proc. Natl. Acad. Sci. USA. 76:4350-4354.

40. Lowry, O. H., N. J. Rosebrough, A. L. Farr, and R. J. Randall. 1951. Protein measurement with the Folin phenol reagent. J. Biol. Chem. 193:265-275.

41. Hjelm, H., K. Hjelm, and J. Sjoquist. 1972. Protein A from staphylococcus aureus: its isolation by affinity chromatography and its use as an immunosorbent for isolation of immunoglobulins. FEBS (Fed. Eur. Biochem. Soc.) Lett. 28:73-76.

42. Rico, J., and R. Hall. 1988. Lymphoblastoid cell lines from patients with bullous pemphigoid produce anti-basement membrane zone antibodies. J. Invest. Dermatol. 90:602. (Abstr.) 